\title{
Analisis Pendapatan Usahatani Labu Siam Di Desa Harusan Kecamatan Amuntai Tengah Kabupaten Hulu Sungai Utara Propinsi Kalimantan Selatan
}

\section{(The Income Analysis Siam Pumpkin Farming In Harusan Village District Of Central Amuntai Hulu Sungai Utara Regency South Kalimantan Province)}

\author{
Muhammad Haris \\ Program Studi Agribisnis, Sekolah Tinggi Ilmu Pertanian Amuntai \\ harism@yahoo.co.id
}

\begin{abstract}
ABSTRAK
Pengembangan pertanian bertujuan untuk meningkatkan produksi pertanian untuk memenuhi kebutuhan pangan dan kebutuhan industri dalam negeri, meningkatkan ekspor, meningkatkan pendapatan petani, memperluas peluang kerja dan mendukung peluang. Produksi sayuran di Hulu Sungai Utara sangat beragam, seperti waluh atau dikenal dengan labu. Penelitian ini bertujuan (i) mengetahui biaya total, penerimaan dan pendapatan yang diperoleh petani dari usahatani sampingan di Desa Harusan, (ii) mengetahui usahatani sampingan yang memberikan pendapatan petani yang terbesar di Desa Harusan. Penelitian dimulai dari Mei - Agustus 2011, yaitu mulai dari persiapan hingga penyusunan laporan. Jenis data yang dikumpulkan dalam penelitian ini terdiri dari data primer dan data sekunder. Pengambilan sampel untuk petani adalah semua petani yang menghasilkan labu dan ubi Alabio di Desa Harusan Kecamatan Amuntai Tengah. Dari total populasi sebanyak 78 petani yang menanam produk samping squash yang tersebar di Desa Harusan diambil secara acak dengan metode purposive random sampling. Total biaya rata-rata labu pertanian adalah Rp. 936.600,39, - Rata-rata penerimaan labu petani adalah Rp. 1,466,111.11, -. Rata-rata penghasilan petani labu adalah Rp. 1,381.791,67, -. Petani yang menanam labu di Desa Harusan memberikan pendapatan besar bagi petani.
\end{abstract}

Kata kunci: Labu, usahatani, petani, pendapatan, total.

\begin{abstract}
Agricultural development aims to increase agricultural production to meet the food needs and needs of the domestic industry, increase exports, increase farmer incomes, expand employment opportunities and support opportunities. Vegetable production in North Hulu Sungai is very diverse, such as pumpkin or known as pumpkin. This study aims to (i) find out the total costs, income and income obtained by farmers from side farming in Harusan Village, (ii) find out the side farms that provide the largest farmers' income in Harusan Village. The study began from May - August 2011, namely from preparation to preparation of reports. The type of data collected in this study consists of primary data and secondary data. Sampling for farmers is all farmers who produce Alabio pumpkins and yams in Harusan Village, Central Amuntai District. From a total population of 78 farmers who planted squash by-products spread in Harusan Village, they were taken randomly using purposive random sampling method. The total cost of an average pumpkin is $R p .936,600.39$, - The average receipt of farmer's pumpkin is Rp. 1,466,111.11, -. The average income of pumpkin farmers is Rp. 1,381,791.67, -. Farmers who plant pumpkins in Harusan Village provide a large income for farmers.
\end{abstract}

Keywords: Pumpkin, farming, farmers, income, total.

\section{PENDAHULUAN}

Pengembangan pertanian diarahkan untuk meningkatkan produksi pertanian guna memenuhi kebutuhan pangan dan kebutuhan industri dalam negeri, meningkatkan ekspor, meningkatkan pendapatan petani, memperluas kesempatan kerja dan mendukung kesempatan berusaha (Harold, 1992).

Tujuan pembangunan pertanian adalah meningkatkan produksi, baik untuk memenuhi kebutuhan konsumsi masyarakat yang harus meningkat, memenuhi kebutuhan bahan baku untuk industri dalam negeri maupun perolehan devisa negara. Selain itu 
juga sekaligus bertujuan memperluas kesempatan kerja, meningkatkan pendapatan petani, pekebun, peternak dan nelayan, mendorong pemerataan pendapatan dan pemerataan kesempatan berusaha, serta mendukung pembangunan daerah dengan tetap memperhatikan kelestarian sumber daya (Harahap, 1985).

Produksi sayuran di Kabupaten Hulu Sungai Utara sangat beragam, diantaranya adalah labu siam atau dikenal dengan sebutan waluh. Labu siam diusahakan petani pada lahan lebak yang dangkal atau pada pematang tepatnya pada watun satu, ditanam pada musim kemarau.

Kecamatan Amuntai Tengah merupakan salah satu daerah penghasil labu siam. Produktivitas labu siam di Kecamatan Amuntai Tengah semakin meningkat dengan luas tanam yang diperkecil dari tahun sebelumnya. Peningkatan produksi labu siam mampu memberikan kontribusi yang cukup besar bagi pendapatan petani.

Desa Harusan merupakan salah satu penghasil usahatani sampingan seperti labu siam, ubi alabio, jagung, kacang panjang, bengkoang, mentimun air, dan lain-lain. Usahatani labu siam merupakan usahatani sampingan yang cukup besar dihasilkan di Desa Harusan. Sedangkan usahatani sampingan lainnya seperti ubi alabio, jagung, kacang panjang, bengkoang, mentimun air, dan lain-lain hanya sedikit dan diusahakan hanya untuk konsumsi saja.

Penelitian ini bertujuan (i) mengetahui biaya total, penerimaan dan pendapatan yang diperoleh petani dari usahatani sampingan di Desa Harusan, (ii) mengetahui usahatani sampingan yang memberikan pendapatan petani yang terbesar di Desa Harusan.

\section{METODE PENELITIAN}

\section{Tempat dan Waktu}

Penelitian dilaksanakan pada usahatani labu siam di Desa Harusan Kecamatan Amuntai Tengah Kabupaten Hulu Sungai Utara. Waktu penelitian dimulai dari bulan Mei sampai Agustus 2011, yaitu mulai dari persiapan sampai dengan penyusunan laporan.

\section{Jenis Dan Sumber Data}

Jenis data yang dikumpulkan dalam penelitian ini terdiri dari data primer dan data sekunder. Pengumpulan data primer dilakukan melalui wawancara langsung dengan para responden dengan berpedoman pada daftar pertanyaan yang telah disiapkan. Sedangkan data sekunder dikumpulkan dari berbagai dinas atau instansi yang ada kaitannya dengan penelitian serta pustaka yang ada kaitannya dengan penelitian.

\section{Metode Pengumpulan Data}

Pengambilan contoh untuk petani adalah seluruh petani yang memproduksi labu siam dan ubi Alabio di Desa Harusan Kecamatan Amuntai Tengah. Dari jumlah populasi sebanyak 78 petani usahatani sampingan labu siam yang tersebar di Desa Harusan diambil secara acak dengan metode purposif random sampling.

\section{Analisis Data}

Data yang diperlukan dari petani responden diolah dan dianalisis sesuai dengan tujuan penelitian. Biaya total yang terdiri dari biaya eksplisit dan biaya implisit dihitung menggunakan rumus :

Keterangan :

$$
\mathrm{TC}=\mathrm{TCe}+\mathrm{TCi}
$$

$\mathrm{TC}=$ Biaya total $(\mathrm{Rp} / \mathrm{th})$

$\mathrm{TCe}=$ Biaya eksplisit total $(\mathrm{Rp} / \mathrm{th})$

$\mathrm{TCi}=$ Biaya implisit total $(\mathrm{Rp} / \mathrm{th})$

Total biaya eksplisit dihitung mengunakan rumus :

$$
\text { TCe = Xnwyi . Hxnw }
$$

Keterangan :

$\mathrm{TCe}=$ Biaya eksplisit ( $\mathrm{Rp} / \mathrm{th})$.

$\mathrm{X}_{\text {n.w.yi }}=$ Menyatakan banyaknya barang dan jasa input $\mathrm{x}$ ke $-\mathrm{n}$ yang dipergunakan bagi penyelenggaraan cabang usaha tani yi tersebut.

$\mathrm{H}_{\mathrm{xnw}}=$ Menyatakan harga barang dan jasa $\mathrm{x}$ ke-n yang dibeli / diperoleh pada saat ke w.

Total biaya implisit dihitung menggunakan rumus :

$$
\mathrm{TCi}=\mathrm{X}_{\text {n.w.yi }} \cdot \mathrm{H}_{\mathrm{xnw}}
$$

Keterangan :

$\mathrm{TCi}=$ Biaya Implisit $(\mathrm{Rp} / \mathrm{th})$

$X_{\text {n.w.yi }}=$ Menyatakan banyaknya barang dan jasa input $x$ ke-n yang dipergunakan bagi 
penyelenggaraan cabang usaha tani yi tersebut.

$\mathrm{H}_{\mathrm{xnw}}=$ Menyatakan harga barang dan jasa x ke-n yang dibeli / diperoleh pada saat ke w.

Biaya ekplisit pada usaha tani labu siam meliputi sarana produksi dan biaya penyusutan. Sedangkan biaya implisit meliputi biaya pengadaan benih, biaya bunga modal sendiri dan biaya tenaga kerja dalam keluarga (TKDK).

Menghitung biaya penyusutan barang dan modal dalam usaha tani labu siam selama 1 tahun adalah :

$$
D u=\frac{N a-N s}{U p} \times L e
$$

Keterangan :

$\mathrm{Du}=$ Besarnya nilai penyusutan barang modal tetap yang dipergunakan khususnya untuk usaha tertentu selama masa produksi (bulan).

$\mathrm{Na}=$ Besarnya nilai awal barang modal tetap, yang sama dengan harga pengadaan atau harga pembeliannya (Rp).

Ns = Besarnya nilai sisa dari barang modal tetap, yang ditaksir sama dengan harganya pada saat sudah tidak lagi dipergunakan ( $\mathrm{Rp}$ ).

$\mathrm{Up}=$ Umur penggunaan barang modal tetap bersangkutan (tahun).

Le = Lamanya penggunaan efektif barang pada suatu usaha tertentu (tahun).

Besarnya penerimaan selama periode satu tahun dihitung menggunakan rumus :

$$
\mathrm{TR}=\mathrm{Py} \cdot \mathrm{Y}
$$

Keterangan :

$\mathrm{TR}=$ Penerimaan total $(\mathrm{Rp} / \mathrm{th})$.

Py = Harga produksi labu siam $(\mathrm{Rp} / \mathrm{Kg})$.

$\mathrm{Y} \quad=$ Hasil produksi labu siam $(\mathrm{Kg})$.

Pendapatan usahatani adalah selisih

antara penerimaan total dengan biaya eksplisit dihitung menggunakan rumus :

$$
\mathrm{FI}=\mathrm{TR}-\mathrm{TCe}
$$

Keterangan :

FI = Pendapatan usahatani $(\mathrm{Rp})$.

$\mathrm{TR}=$ Penerimaan $(\mathrm{Rp})$.

Tce $=$ Biaya eksplisit $(\mathrm{Rp} / \mathrm{th})$.

Tujuan kedua yaitu mengetahui usahatani sampingan apa yang memberikan pendapatan petani yang terbesar dianalisis secara deskriptif.

\section{HASIL DAN PEMBAHASAN}

\section{Analisis Biaya, Penerimaan dan Pendapatan}

\section{Biaya Eksplisit}

Biaya eksplisit adalah biaya yang benar-benar dikeluarkan secara nyata. Biaya yang digunakan dalam pelaksanaan usahatani Labu Siam adalah biaya penyusutan terdiri dari penyusutan alat dan perlengkapan yang digunakan seperti parang dan linggis, biaya sarana produksi terdiri dari sarana produksi benih, parang dan linggis dan biaya bibit. Rincian biaya eksplisit Labu Siam dilihat pada Tabel 1.

Tabel 1. Rata-Rata Biaya Eksplisit Usahatani Labu Siam Di Desa Harusan.

\begin{tabular}{llcc}
\hline \multirow{2}{*}{ No } & \multicolumn{1}{c}{ Biaya Eksplisit } & \multicolumn{2}{c}{ Labu Siam } \\
\cline { 3 - 4 } & & Jumlah Biaya & $(\%)$ \\
\hline 1. & Biaya penyusutan & $2.430,56$ & 2,88 \\
2. & Biaya sarana produksi & $72.055,55$ & 85,46 \\
3. & Biaya bibit & $9.833,33$ & 11,66 \\
4. & Biaya perlengkapan yang habis sekali pakai &. &. \\
\hline Jumlah & $84.319,44$ & 100,00 \\
\hline
\end{tabular}

Berdasarkan Tabel 1 biaya eksplisit terbesar pada usahatani Labu Siam adalah biaya sarana produksi yaitu sebesar $\mathrm{Rp}$. $72.055,55$ dengan persentase $85,46 \%$.

\section{Biaya Implisit}


Biaya Implisit merupakan biaya yang tidak benar-benar dikeluarkan secara nyata oleh petani tetapi tetap diperhitungkan sebagai biaya. Biaya implisit pada usahatani Labu Siam adalah biaya bunga modal, biaya
Tenaga Kerja Dalam Keluarga (TKDK) dan biaya sewa lahan. Rincian biaya implisit usahatani labu siam dapat dilihat pada Tabel 2.

Tabel 2. Rata-Rata Biaya Implisit Usahatani Labu Siam Di Desa Harusan

\begin{tabular}{llcc}
\hline \multirow{2}{*}{ No } & \multicolumn{1}{c}{ Biaya Implisit } & \multicolumn{2}{c}{ Labu Siam } \\
\cline { 3 - 4 } & \multicolumn{1}{c}{ Jumlah Biaya } & $(\%)$ \\
\hline 1. & Biaya bunga modal sendiri & $5.059,17$ & 0,59 \\
2. & Biaya TKDK & $338.888,89$ & 39,76 \\
3. Biaya sewa lahan sendiri & $508.333,33$ & 59,65 \\
4. & Biaya bibit & - & - \\
\hline Jumlah & $852.281,39$ & 100,00 \\
\hline
\end{tabular}

Berdasarkan Tabel 2 biaya implisit pada usahatani labu siam yang paling besar adalah biaya sewa lahan sendiri dengan jumlah Rp. 508.333,33 dengan persentase $59,64 \%$, sedangkan biaya yang terkecil adalah biaya bunga modal sendiri dengan jumlah Rp. 5.059,17 dengan persentase 0,59 $\%$. Untuk lebih jelasnya akan diuraikan secara singkat mengenai komponenkomponen biaya yang termasuk biaya implisit.

\section{Biaya Tenaga Kerja Dalam Keluarga (TKDK)}

Tenaga kerja dalam sebuah usahatani pada hakekatnya terbagi menjadi dua bagian yaitu tenaga kerja luar keluarga dan tenaga kerja dalam keluarga. Petani yang mengusahakan usahatani sampingan di Desa Harusan hanya menggunakan tenaga kerja dalam keluarga karena usahatani sampingan yang diusahakan tidak besar. Tenaga kerja dalam keluarga terdiri dari laki-laki dan perempuan yang semuanya bekerja untuk penyelengaraan usahatani mulai dari pengolahan tanah sampai panen. Rata-rata biaya tenaga kerja dalam keluarga dapat dilihat pada Tabel 3 .

Tabel 3. Rata-Rata Biaya Tenaga Kerja Dalam Keluarga Di Desa Harusan

\begin{tabular}{ccc}
\hline No & Uraian & Jumlah Biaya (Rp) \\
\hline 1. & Biaya Tenaga Kerja Dalam Keluarga & $338.888,89$ \\
\hline
\end{tabular}

\section{Biaya Bunga Modal Sendiri}

Faktor produksi modal kerja yang dimaksud disini adalah seluruh biaya yang dikeluarkan untuk pengadaan sarana produksi dan biaya lainnya yang terdiri dari biaya alat dan perlengkapan serta biaya bibit.
Biaya bunga modal sendiri diperhitungkan berdasarkan tingkat suku bunga untuk Usaha Kecil dan Menengah (UKM) pada Bank Rakyat Indonesia sebesar $12 \%$ pertahun atau $1 \%$ perbulan. Rata-rata bunga modal sendiri dapat dilihat pada Tabel 4.

Tabel 4. Rata-Rata Biaya Bunga Modal Sendiri Di Desa Harusan

\begin{tabular}{ccc}
\hline No & Uraian & Jumlah Biaya (Rp) \\
\hline 1. & Biaya Bunga Modal Sendiri & $5.059,17$ \\
\hline
\end{tabular}

\section{Biaya Sewa Lahan Sendiri}

Sewa lahan yang berlaku di Desa Harusan adalah Rp. 150.000,- / 0,03 ha, untuk menjadi kapasitas lahan yang bisa disewakan maka kondisinya harus siap pakai dalam arti 
sudah bersih dan sudah siap untuk usahatani. Untuk lebih jelasnya rata-rata biaya sewa lahan dapat dilihat pada Tabel 5.

Tabel 5. Rata-Rata Biaya Sewa Lahan Di Desa Harusan

\begin{tabular}{lcc}
\hline No & Uraian & Jumlah Biaya $(\mathrm{Rp})$ \\
\hline 1. & Biaya Sewa Lahan Sendiri & $508.333,33$ \\
\hline
\end{tabular}

\section{Biaya Bibit}

Bibit merupakan faktor produksi yang mutlak harus ada dimana kegunaannya sudah cukup jelas yaitu sebagai cikal bakal suatu tanaman. Bibit bisa dibeli atau bisa menggunakan sisa tanaman terdahulu yang sudah disortir untuk menjadi bibit. Apabila bibit dibeli maka perhitungannya dimasukkan kedalam biaya eksplisit dan apabila bibit berasal dari sisa tanaman terdahulu yang sudah disortir maka perhitungannya dimasukkan ke dalam biaya implisit. Rata-rata biaya bibit yang dikeluarkan petani responden dapat dilihat pada Tabel 6.

Tabel 6. Rata-Rata Biaya Bibit Di Desa Harusan

\begin{tabular}{ccc}
\hline No & Uraian & Jumlah Biaya (Rp) \\
\hline 1. & Biaya Bibit & $9.833,33$ \\
\hline
\end{tabular}

\section{Biaya Total}

Dalam pehitungan dari usahatani sampingan ini biaya total merupakan penjumlahan dari biaya eksplisit dan biaya implisit. Rincian biaya total rata-rata dapat dilihat pada Tabel 7.

Tabel 7. Rata-Rata Biaya Total Usahatani Labu Siam dan Ubi Alabio Di Desa Harusan.

\begin{tabular}{lrrr}
\hline \multirow{2}{*}{ No } & \multirow{2}{*}{ Uraian Biaya } & \multicolumn{2}{c}{ Labu Siam } \\
\cline { 2 - 3 } & & Jumlah Biaya & $(\%)$ \\
\hline 1. & Biaya Eksplisit & $84.319,44$ & 9,00 \\
2. & Biaya Implisit & $852.281,39$ & 91,00 \\
\hline Jumlah & $936.600,83$ & 100,00 \\
\hline
\end{tabular}

Berdasarkan tabel diatas biaya terbesar yang harus dikeluarkan petani responden pada usahatani labu siam adalah biaya implisit yaitu sebesar Rp. 852.281,39,- / usahatani dengan persentase $91,00 \%$ dan

\section{Penerimaan}

Penerimaan usahatani adalah besarnya produksi dari usahatani dikalikan dengan harga yang berlaku ditingkat petani. Hasil rata-rata jumlah produksi usahatani labu siam adalah 209,44 biji/usahatani dan rata-rata biaya yang terkecil adalah biaya eksplisit yaitu sebesar Rp. 84.319,44,- / usahatani dengan persentase $9,00 \%$. Jadi biaya total yang dikeluarkan petani adalah Rp. 936.600,83.

harga jual ditingkat petani adalah Rp. 7.000,/biji/usahatani. Penerimaan rata-rata usahatani labu siam adalah sebesar Rp. 1.466.111,11,-/usahatani. Penerimaan ratarata petani labu siam di Desa Harusan untuk lebih jelasnya dapat dilihat pada Tabel 8 . 
Tabel 8. Rata-Rata Penerimaan Petani Usahatani Labu Siam Di Desa Harusan

\begin{tabular}{lcr}
\hline No & Uraian & Labu Siam \\
\hline 1. & Produksi & 209,44 \\
2. & Harga & 7.000 \\
\hline Penerimaan & & $1.466 .111,11$ \\
\hline
\end{tabular}

Penerimaan dari usahatani sangat ditentukan oleh harga produksi yang tinggi disamping hasil produksi yang maksimal, maka semakin tinggi harga produksi semakin besar penerimaan yang diperoleh petani.

\section{Pendapatan}

Pendapatan usahatani adalah besarnya penerimaan dikurangi biaya eksplisit. Pendapatan rata-rata usahatani labu siam adalah Rp. 1.381.791,67,-/usahatani. Untuk lebih jelasnya dapat dilihat pada Tabel 9.

Tabel 9. Rata-Rata Pendapatan Petani Responden Usahatani Labu Siam Di Desa Harusan

\begin{tabular}{llr}
\hline No & Uraian & Labu Siam \\
\hline 1. & Penerimaan & $1.466 .111,11$ \\
2. & Biaya eksplisit & $84.319,44$ \\
\hline Pendapatan & $1.381 .791,67$ \\
\hline
\end{tabular}

Perhitungan analisis biaya, peneriman dan pendapatan usahatani labu siam di Desa Harusan diperoleh hasil bahwa petani yang mengusahakan usahatani labu siam di Desa Harusan memberikan pendapatan cukup besar bagi petani dengan penerimaan ratarata petani sebesar Rp. 1.466.111,11 per usahatani dan biaya eksplisit rata-rata sebesar Rp. 84.319,44 per usahatani. Petani yang mengusahakan usahatani labu siam pendapatannya sebesar Rp. 1.381.791,67,/usahatani.

\section{KESIMPULAN}

Biaya total rata-rata pada usahatani labu siam adalah Rp. 936.600,39,-. Penerimaan rata-rata usahatani labu siam adalah Rp. 1.466.111,11,-. Pendapatan ratarata usahatani labu siam adalah $\mathrm{Rp}$. 1.381.791,67,-. Petani yang mengusahakan usahatani labu siam di Desa Harusan memberikan pendapatan cukup besar bagi petani.

\section{DAFTAR PUSTAKA}

Halcrow, G. Harold. 1992. Ekonomi Pertanian. Universitas Muhammadiyah. Malang.
Harahap, Hasrul. 1985. Perkebunan dan peranannya dalam perekonomian Indonesia. Agroekonomika.

Kasim, A. Syarifudin. 1995. Pengantar Ekonomi Produksi. Lambung Mangkurat University Press. Fakultas Pertanian UNLAM. Banjarbaru.

Kasim, A. Syarifudin.1997. Petunjuk Praktis Menghitung Keuntungan dan Pendapatan Petani. Fakultas Pertanian UNLAM. Banjarbaru.

Kasim, A. Syarifudin. 2004. Petunjuk Praktis Menghitung Keuntungan dan Pendapatan Usahatani. Fakultas Pertanian UNLAM. Banjarbaru.

Sadono, S. 2000. Pengantar Teori Ekonomi Mikro. PT.Raja Grafindo Persada. Jakarta.

Seto, Sagung. 2001. Pangan dan Gizi Teknologi Pertanian. ITB. Bogor.

Sudarto, Yudo. 2000. Budidaya Waluh. Kanisius. Yogyakarta. 